\title{
A comparison between the Strep A Rapid Test Device and conventional culture for the diagnosis of streptococcal pharyngitis
}

\author{
Kevin R Forward MD FRCPC ${ }^{1,2}$, David Haldane MB FRCPC ${ }^{1,2}$, Duncan Webster MD FRCPC ${ }^{1}$, \\ Carolyn Mills MLT ${ }^{1}$, Cheryl Brine $\mathrm{MLT}^{1}$, Diane Aylward $\mathrm{MLT}^{1}$
}

\begin{abstract}
KR Forward, D Haldane, D Webster, C Mills, C Brine, D Aylward. A comparison between the Strep A Rapid Test Device and conventional culture for the diagnosis of streptococcal pharyngitis. Can J Infect Dis Med Microbiol 2006;17(4):221-223.
\end{abstract}

BACKGROUND: Rapid antigen detection tests are frequently used to diagnose pharyngitis due to Streptococcus pyogenes. Because a large number of kits are available commercially, performance characteristics may vary considerably. The present study evaluated one such kit currently in use in Canadian laboratories for which published evaluations are not available.

OBJECTIVE: To evaluate the performance characteristics of the Strep A Rapid Test Device (SARTD) (Nova Century Scientific Inc, Canada).

METHODS: Pharyngeal swabs from 818 patients with suspected streptococcal pharyngitis were tested. Swabs were initially inoculated onto the surface of a blood agar plate and then used to perform the rapid antigen test. The test was performed in accordance with the product monograph. Beta-hemolytic colonies were identified as $S$ pyogenes using conventional means.

RESULTS: Four hundred ninety specimens were obtained from children and 328 from adults. S pyogenes was recovered from 171 (21\%) patients. The SARTD detected S pyogenes antigens in 123 of $171 \mathrm{spec}-$ imens from which $S$ pyogenes was isolated on culture; the screen was negative in 610 of 647 specimens from which cultures were negative. The positive and negative predictive values of the SARTD were $76.9 \%$ and $92.7 \%$, respectively.

CONCLUSIONS: The SARTD was much less sensitive (72\%) than was suggested in the product monograph (90\%). Laboratories should vigorously evaluate such products in-house, optimize specimen collection and transport, and choose more sensitive kits for use.

Key Words: Antigen detection; Pharyngitis; Streptococcus pyogenes

Streptococcal pharyngitis remains an important cause of morObidity and is one of the leading reasons for physician visits (1). Although there are clinical algorithms to assess the probability that pharyngitis is due to Streptococcus pyogenes, the diagnosis of streptococcal pharyngitis cannot be made on clinical grounds alone (2,3). Physicians are encouraged to submit throat swabs for antigen detection, culture or both $(4,5)$. Same-day testing by antigen detection can be an important strategy to reduce unnecessary antibiotic use. In many settings, patient care may be improved, and fewer laboratory resources may be used
Une comparaison entre le Strep A Rapid Test Device et la culture traditionnelle pour diagnostiquer une pharyngite streptococcique

HISTORIQUE : Les tests de détection rapide des antigènes sont souvent utilisés pour diagnostiquer une pharyngite secondaire au Streptococcus pyogenes. Puisqu'il existe de nombreuses trousses sur le marché, leurs caractéristiques de rendement peuvent varier considérablement. La présente étude a consisté à évaluer l'une de ces trousses utilisée dans les laboratoires canadiens et pour laquelle aucune évaluation n'a encore été publiée.

OBJECTIF : Évaluer les caractéristiques de rendement du Strep A Rapid Test Device (SARTD) (ACON Laboratories, États-Unis).

MÉTHODOLOGIE : Des échantillons pharyngés de 818 patients atteints d'une pharyngite à streptocoque présumée ont été évalués. Les prélèvements ont d'abord été inoculés sur la surface d'une plaque à gélose au sang, puis utilisés pour exécuter le test d'antigène rapide. Les tests ont été effectués conformément à la monographie du produit. À l'aide des moyens traditionnels, on a découvert que les colonies béta-hémolytiques étaient des $S$ pyogenes.

RÉSULTATS : Quatre cent quatre-vingt-dix échantillons (490) ont été prélevés chez des enfants et 328, chez des adultes. On a décelé le $S$ pyogenes chez $171(21 \%)$ patients. Le SARTD a permis de déceler des antigènes au $S$ pyogenes pour 123 des 171 échantillons dans lesquels on avait isolé un $S$ pyogenes en culture. Le dépistage était négatif pour 610 des 647 échantillons dans lesquels les cultures étaient négatives. Les valeurs prédictives positives et négatives du SARTD étaient de 76,9\% et de $92,7 \%$, respectivement.

CONCLUSIONS : Le SARTD était beaucoup moins sensible (72\%) que le laissait supposer la monographie du produit (90\%). Les laboratoires devraient évaluer vigoureusement ces produits à l'interne, optimiser la collecte et le transport des échantillons et utiliser des trousses plus sensibles.

when streptococcal antigen testing is performed at the point of care rather than sent to a clinical laboratory.

The performance characteristics of rapid antigen tests vary in both sensitivity and specificity (6-10). When tests are highly sensitive and the pretest probability is low, supplemental culture may not be necessary if the screening test is negative (4). Falsepositive tests may lead to unnecessary antibiotic use.

We compared the results of a commercially available screening device with conventional culture to evaluate its performance characteristics.

${ }^{1}$ Department of Pathology and Laboratory Medicine, Queen Elizabeth II Health Sciences Centre; ${ }^{2}$ Dalhousie University, Halifax, Nova Scotia Correspondence: Dr Kevin R Forward, Division of Microbiology, Queen Elizabeth II Health Sciences Centre, 5788 University Avenue, Halifax,

Nova Scotia B3H 1V8. Telephone 902-473-4109, fax 902-473-4432, e-mail kevin.forward@cdha.nshealth.ca

Received for publication May 4, 2006. Accepted June 20, 2006 
TABLE 1

Performance characteristics of the Strep A Rapid Test Device* compared with conventional culture

\begin{tabular}{|c|c|c|c|c|c|c|c|c|c|}
\hline & $\begin{array}{c}\text { Culture-positive } \\
(\%)\end{array}$ & $\begin{array}{l}\text { Culture-positive, } \\
\text { screen-positive (n) }\end{array}$ & $\begin{array}{l}\text { Culture-negative, } \\
\text { screen-positive (n) }\end{array}$ & $\begin{array}{c}\text { Culture-positive, } \\
\text { screen-negative (n) }\end{array}$ & $\begin{array}{l}\text { Culture-negative, } \\
\text { screen-negative (n) }\end{array}$ & $\begin{array}{c}\text { Sensitivity } \\
(\%)\end{array}$ & $\begin{array}{c}\text { Specificity } \\
(\%)\end{array}$ & $\begin{array}{l}\text { PPV } \\
(\%)\end{array}$ & $\begin{array}{l}\text { NPV } \\
(\%)\end{array}$ \\
\hline Adults $(n=328)$ & 16.2 & 43 & 14 & 10 & 261 & 81.1 & 94.9 & 75.4 & 96.3 \\
\hline
\end{tabular}

*Nova Century Scientific Inc, Canada. NPV Negative predictive value; PPV Positive predictive value

\section{METHODOLOGY}

\section{Study design}

In February and March 2006, pharyngeal swabs from children (16 years of age or younger) and adults received at the Queen Elizabeth II Health Sciences Clinical Microbiology Laboratory (Halifax, Nova Scotia) were subjected to both conventional culture and the Strep A Rapid Test Device (SARTD) (distributed in Canada by Nova Century Scientific Inc, Canada), the latter being a chromatographic immunoassay used to detect group A streptococcus. Swabs were received in clear Amies Transport Medium (M40 Transystem, Copan Innovation, USA). The swab was used to inoculate a 5\% sheep blood agar plate (Oxoid, Canada) and then screened with the study device.

\section{Culture and identification}

Plates were incubated anaerobically at $35^{\circ} \mathrm{C}(11)$ and examined at $24 \mathrm{~h}$ and $48 \mathrm{~h}$; typical colonies that were catalase-negative and exhibited typical Gram stain morphology were tested for the presence of pyrrolidonyl peptidase by using the PYR test (Remel, USA) as per the manufacturer's instructions (12). The screening test and the colony work-up were performed by different technologists who had no knowledge of prior results.

\section{Rapid antigen detection test}

The SARTD was used according to the manufacturer's recommendations. Briefly, kits were stored at $4^{\circ} \mathrm{C}$ and brought to room temperature before testing. To extract the group A streptococcal carbohydrate antigen, five drops of reagent $\mathrm{A}$ and five drops of reagent $\mathrm{B}$ were added to the test kit chamber, and the swab was then inserted. The swab was agitated and left to sit for $1 \mathrm{~min}$ to $5 \mathrm{~min}$, removed halfway, and rotated against the chamber ribs to release liquid into the chamber. The chamber valve was subsequently opened, allowing liquid to flow from the chamber along a test strip to an indicator coated with antibody to the group A streptococcal antigen. At $5 \mathrm{~min}$, the strip was observed for the presence of a red line in the control and test regions. The appearance of two distinct red lines was interpreted as a positive result, while a single red line in the control region was considered to be a negative test result. If the positive control line did not appear, then the test was considered invalid.

\section{Statistical analysis}

Sensitivity, specificity and predictive values were calculated on the basis of the definition and formulas presented in the study by Ilstrup (13).

\section{RESULTS}

Four hundred ninety specimens originated from children and 328 from adults (Table 1). S pyogenes was recovered from $171(21 \%)$ patients. The SARTD detected group A streptococcal antigens in 123 of 171 specimens from which $S$ pyogenes was isolated on culture; the screen was negative in 610 of 647 specimens from which cultures were negative. The rapid screen was positive on 37 occasions when cultures were negative. Overall, the positive and negative predictive values of the SARTD were $76.9 \%$ and $92.7 \%$, respectively (positive predictive values were $77.7 \%$ for children and $75.4 \%$ for adults; negative predictive values were $90.2 \%$ for children and $96.3 \%$ for adults). The test detected a higher proportion of adults with positive cultures than did conventional culture $(81.1 \%$ versus $67.8 \%)$, but this did not reach statistical significance. There were no equivocal test results or instances where the control failed to turn positive.

\section{DISCUSSION}

A number of kits have been marketed for the detection of group A streptococcal antigens on throat swabs (6-10). Many of these products have not been subjected to peer-reviewed study. Typically, those in wider use have reported sensitivities of approximately $90 \%$ and specificities of approximately $95 \%$ (7). When tests are less sensitive or specific, the utility of antigen testing is reduced and their use is less easily justified. When rapid tests are highly sensitive, subsequent cultures may be unnecessary. As new tests are marketed, their performance characteristics should be carefully evaluated, especially when the results of the prior evaluations undertaken for licensing purposes are not published in peer-reviewed journals.

In all, we examined 818 specimens submitted in Amies Transport Medium without charcoal. Overall, the positivity rate was $22 \%$ in children and $15.6 \%$ in adults. These rates, particularly the adult positivity rates, were somewhat higher than we had anticipated. This may reflect the time of the year that the study was conducted (mid-winter). The SARTD detected S pyogenes antigens in 123 of 171 (71.9\%) specimens. The test was more often correctly positive in adults than in children ( $81 \%$ versus $68 \%$ ). It is possible that this may be due to a spectrum bias (ie, the proportion of adults with true pharyngitis, rather than colonization, was greater than that of children), although this seems unlikely. Perhaps adults were more effectively swabbed than children. The overall specificity when clear Amies Transport Medium was used was $94.9 \%$. Because it can be assumed that all patients with a positive antigen test would receive an antibiotic, and because the predictive value of a positive antigen test was $78 \%$, it means that a significant proportion of patients with positive antigen tests would receive unnecessary antibiotics.

The SARTD product monograph indicated an overall sensitivity of $90 \%$ and a specificity of $94 \%$. We considered this test for use in our laboratory because it was of low complexity and was suitable for use with the Amies transport swabs that we use. It is unclear why, in our hands, the test sensitivity differed so markedly from that stated in the product monograph. In the 
manufacturer's unpublished study, 758 swabs were examined by both culture and the SARTD. In all, they detected 240 of 265 swabs from which cultures grew $S$ pyogenes (sensitivity $90 \%$ ). The SARTD was negative in 464 of 494 cases in which $S$ pyogenes was not recovered from culture (specificity $94 \%$ ). The sensitivity of the SARTD was higher for adults than for children ( $81 \%$ versus $68 \%$ ) and is more in line with that stated in the product monograph. The manufacturer's evaluations were carried out in the same manner as ours, that is, with a single swab that was first rolled onto the agar plate and then subjected to antigen extraction. It is our understanding that this evaluation was performed on dry swabs, whereas we used Amies Transport Medium in the present study. The company advises that transport swabs containing modified Stuart's or Amies medium may also be used with this product. It is also suggested that specimens may be held for up to $8 \mathrm{~h}$ at room temperature or refrigerated for $72 \mathrm{~h}$ before testing. The testing we performed was, therefore, entirely in compliance with the product monograph.

We evaluated the SARTD in a manner that reflected our usual laboratory practice (ie, we used single swabs submitted by physicians in the Capital District Health Authority, Halifax, Nova Scotia). The vast majority of swabs are processed on the same day they are collected; those received in the late evening were refrigerated and tested the following morning. Swabs were first used to inoculate the surface of a blood agar plate. Studies have suggested that this has a negligible effect on the recovery of organisms on the swab, and this strategy has not been shown to significantly reduce the proportion of antigen tests that are positive $(14,15)$. The test was simple to use (Clinical Laboratory Improvement Amendments waived) and was performed by laboratory technologists experienced with the use of antigen detection tests. Although the test sometimes produced faint bands, these were interpreted as being positive. We examined the possibility that our identification scheme for beta-hemolytic streptococci may have resulted in false-positive cultures. To exclude this

\section{REFERENCES}

1. Armstrong GL, Pinner RW. Outpatient visits for infectious diseases in the United States, 1980 through 1996. Arch Intern Med 1999;159:2531-6.

2. Centor RM, Witherspoon JM, Dalton HP, Brody CE, Link K. The diagnosis of strep throat in adults in the emergency room. Med Decis Making 1981;1:239-46.

3. Bisno AL. Acute pharyngitis. N Engl J Med 2001;344:205-11.

4. Bisno AL, Gerber MA, Gwaltney JM Jr, Kaplan EL, Schwartz RH. Practice guidelines for the diagnosis and management of group A streptococcal pharyngitis. Infectious Diseases Society of America. Clin Infect Dis 2002;35:113-25.

5. Singh S, Dolan JG, Centor RM. Optimal management of adults with pharyngitis - a multi-criteria decision analysis. BMC Med Inform Decis Mak 2006;6:14.

6. Gerber MA. Comparison of throat cultures and rapid strep tests for diagnosis of streptococcal pharyngitis. Pediatr Infect Dis J 1989;8:820-4.

7. Gerber MA, Shulman ST. Rapid diagnosis of pharyngitis caused by group A streptococci. Clin Microbiol Rev 2004;17:571-80.

8. Daly JA, Korgenski EK, Munson AC, Llausas-Magana E. Optical immunoassay for streptococcal pharyngitis: Evaluation of accuracy with routine and mucoid strains associated with acute rheumatic possibility, we examined 25 consecutive beta-hemolytic streptococci identified as $S$ pyogenes using Gram stain and pyrrolidonyl-beta-naphthylamide tests (data not shown). All were subsequently confirmed using a commercially available agglutination grouping kit (Prolex Streptococcal Grouping Latex Kit, Pro-Lab Diagnostics, Canada).

We used only a single blood agar plate and did not perform a broth enrichment step. It may therefore be argued that the true proportion of throat swabs containing $S$ pyogenes may have been underestimated (10). However, it has also been argued that very small numbers of organisms that can be detected using a culture 'gold standard' may be more likely to represent colonization rather than acute infection.

Kits used for rapid streptococcal antigen testing need to have adequate sensitivity and specificity to inform patient management and to justify the additional expense. Only test kits with very high sensitivities in low prevalence populations (ie, adults) may have a negative predictive value that justifies antigen testing alone without backup culture of initial negative screens. In our setting and using our manner of testing, we did not feel that this kit was adequately sensitive to fulfill that requirement. Numerous streptococcal antigen kits are commercially available, many in the absence of published evaluations of their performance. In many laboratories, the procedures used may differ from the way in which manufacturersponsored evaluations were conducted. Laboratories introducing new kits should perform thorough in-house evaluations before placing them into routine use.

ACKNOWLEDGEMENTS: The authors acknowledge the contribution of Dorothy Gillie, who prepared the manuscript.

ADDENDUM: After reporting our findings to Nova Century Scientific Inc (Burlington, Ontario), their in-house studies confirmed our findings. They have attributed the poor performance to the use of Amies transport semi-solid media and advise that it should no longer be used with the SARTD test kit.

fever outbreak in the intermountain area of the United States. J Clin Microbiol 1994;32:531-2.

9. Fries SM. Diagnosis of group A streptococcal pharyngitis in a private clinic: Comparative evaluation of an optical immunoassay method and culture. J Pediatr 1995;126:933-6.

10. Gieseker KE, MacKenzie T, Roe MH, Todd JK. Comparison of two rapid Streptococcus pyogenes diagnostic tests with a rigorous culture standard. Pediatr Infect Dis J 2002;21:922-7.

11. Lauer BA, Reller LB, Mirrett S. Effect of atmosphere and duration of incubation on primary isolation of group A streptococci from throat cultures. J Clin Microbiol 1983;17:338-40.

12. Wellstood SA. Rapid, cost-effective identification of group A streptococci and enterococci by pyrrolidonyl-beta-naphthylamide hydrolysis. J Clin Microbiol 1987;25:1805-6.

13. Ilstrup DM. Statistical methods in microbiology. Clin Microbiol Rev 1990;3:219-26.

14. Libertin CR, Wold AD, Washington JA II. Effects of trimethoprimsulfamethoxazole and incubation atmosphere on isolation of group A streptococci. J Clin Microbiol 1983;18:680-2.

15. Anhalt JP, Heiter BJ, Naumovitz DW, Bourbeau PP. Comparison of three methods for detection of group A streptococci in throat swabs. J Clin Microbiol 1992;30:2135-8. 


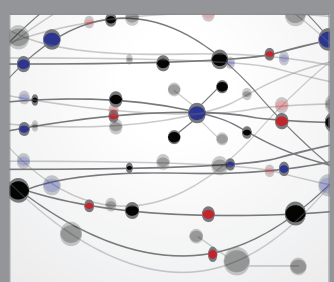

The Scientific World Journal
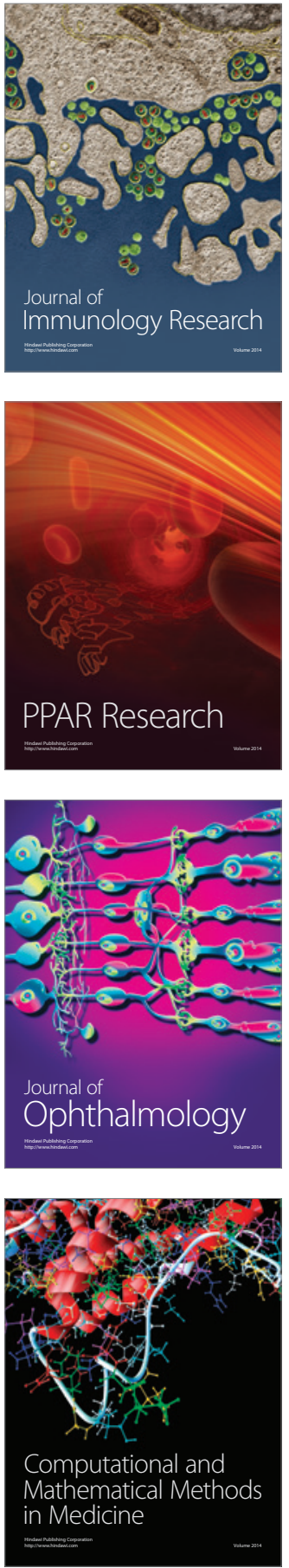

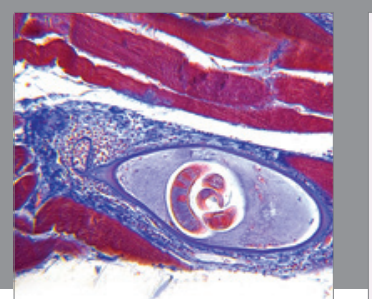

Gastroenterology Research and Practice

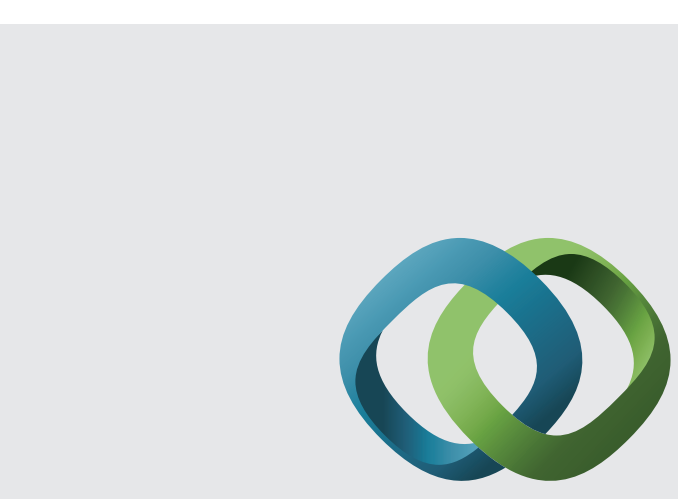

\section{Hindawi}

Submit your manuscripts at

http://www.hindawi.com
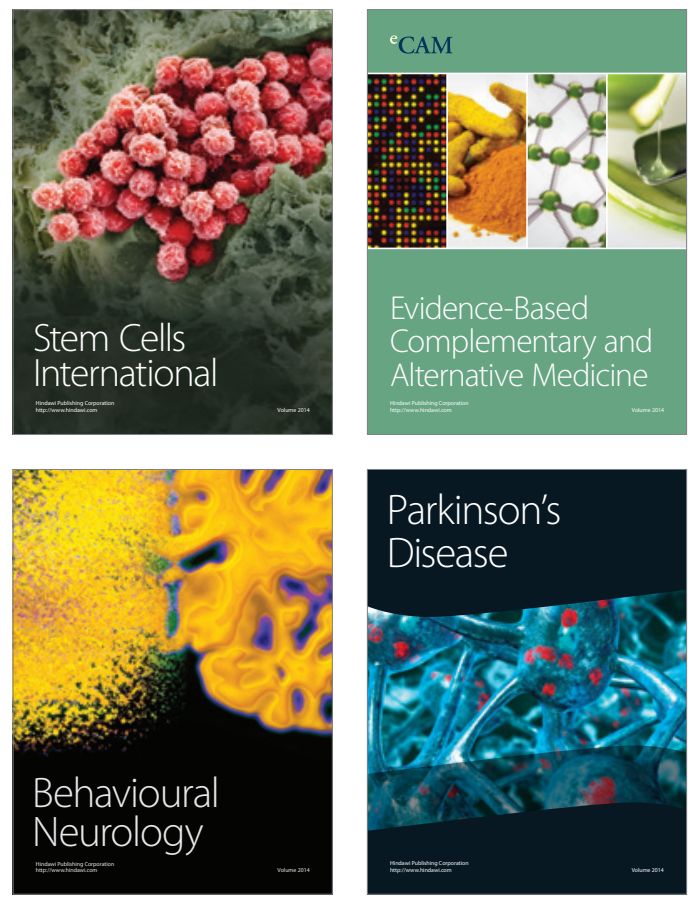
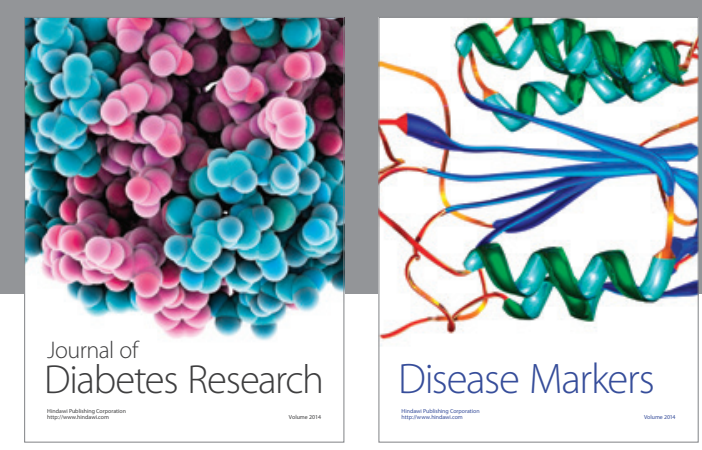

Disease Markers
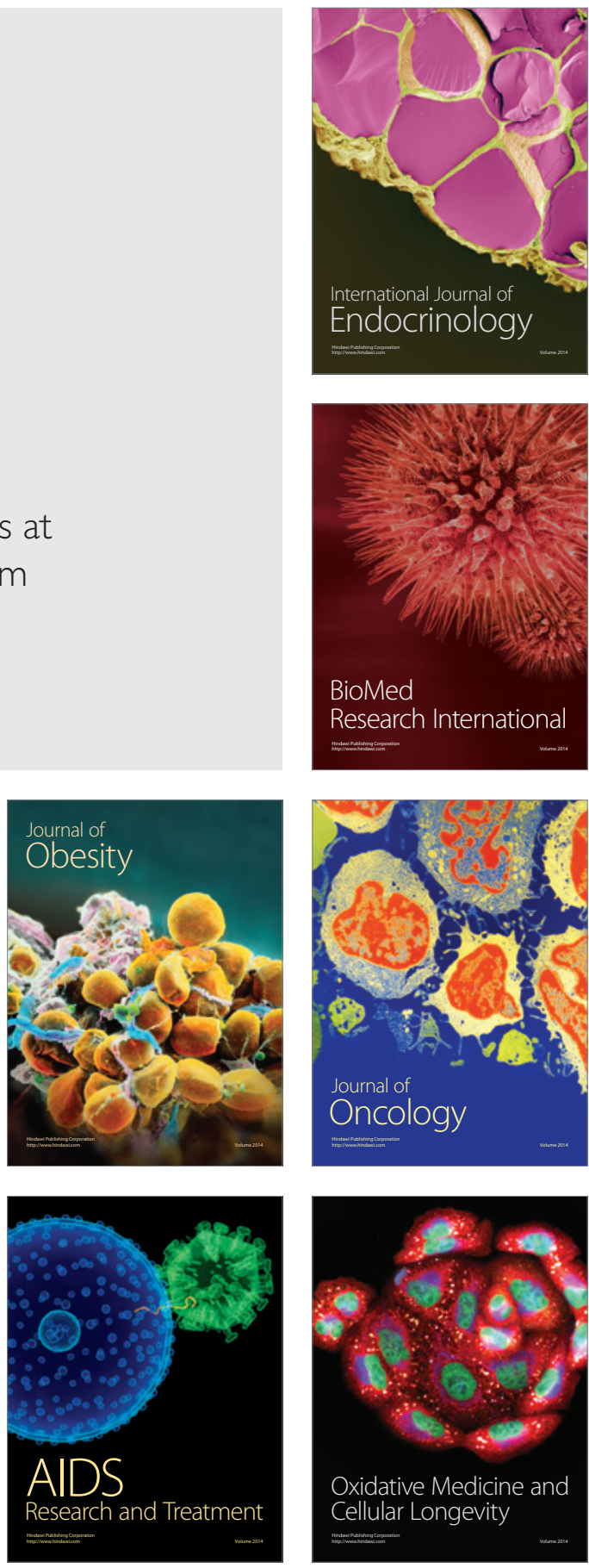